\title{
Formación y evaluación docente basada en un perfil por competencias. Una propuesta desde la práctica reflexiva
}

Arreola Rico, Roxana Lilian

Formación y evaluación docente basada en un perfil por competencias. Una propuesta desde la práctica reflexiva

Revista Educación, vol. 43, núm. 2, 2019

Universidad de Costa Rica, Costa Rica

Disponible en: http://www.redalyc.org/articulo.oa?id=44058158022

DOI: https://doi.org/10.15517/revedu.v43i2.30898

Esta obra está bajo una Licencia Creative Commons Atribución-NoComercial-SinDerivar 3.0 Internacional. 


\title{
Formación y evaluación docente basada en un perfil por competencias. Una propuesta desde la práctica reflexiva
}

\author{
Teacher Education and Assessment based on a Proficiency Profile: A Proposal from a Reflective Practice \\ Perspective
}

Roxana Lilian Arreola Rico

DOI: https://doi.org/10.15517/revedu.v43i2.30898

Universidad Pedagógica Nacional, Ciudad de México, Redalyc: http://www.redalyc.org/articulo.oa?id=44058158022

México

roxarreola@yahoo.com.mx

(iD http://orcid.org/ 0000-0002-3779-1788

Recepción: 03 Noviembre 2017

Aprobación: 27 Mayo 2019

\section{RESUMEN:}

El artículo tiene como objetivo presentar una propuesta para la formación y la evaluación docente, generada a partir de los hallazgos de una investigación desarrollada, cuya metodología fue de corte cualitativo, para ello se retoma el interaccionismo simbólico y la oralidad. En dicho estudio se utilizó como instrumento la entrevista a profundidad, la cual recuperó la narrativa oral de estudiantes de una escuela secundaria de la Ciudad de México. El análisis de resultados se elaboró mediante la definición de categorías empíricas y analíticas a partir de las respuestas de los entrevistados, las cuales aunadas a las categorías teóricas permitieron de-construir, describir, comprender e interpretar lo que sucede en el aula, es decir, comprender los significados de las y los estudiantes, los desempeños docentes, las prácticas educativas y la forma de interactuar de los actores sociales con y en el entorno escolar. Dichos hallazgos referentes a los significados que les representan al estudiantado de secundaria, las prácticas docentes de su profesorado y las características que le otorgan a un buen educador, constituyeron el sustento de la propuesta de intervención aquí desarrollada. La propuesta consiste en formular un sistema de competencias que oriente la formación y la evaluación docente; dicho sistema ofrece un conjunto de competencias el cual permite sustentar la formación de docentes, la práctica educativa y la evaluación de la función docente, así como un conjunto de acciones estratégicas para instrumentar y operar dicho sistema, desde una perspectiva de práctica reflexiva orientada a la transformación de la subjetividad docente.

Palabras clave: Formación docente, Evaluación docente, Competencias, Práctica reflexiva, Subjetividad docente.

\section{Abstract:}

The objective of this article is to provide a proposal for teacher education and assessment based on findings from a qualitative study that considers symbolic interaction and orality. An in-depth interview was used to recover oral narratives of students from a Mexico City high school. Results were analyzed according to a definition of empirical and analytical categories based on interviewee responses, which along with the theoretical categories, allowed us to better deconstruct, describe, understand and interpret classroom interaction. In other words, understand the students, teacher performance, educational practices and interact with social stakeholders within the school environment. Findings address student conceptions about teacher practices and characteristics that they consider necessary to be a good teacher. This study aims at formulating a system of guiding skills for teacher education and assessment as well as strategic actions for this system based on reflexive teaching practices focusing on teacher subjectivity.

KEYWORDs: Teacher Education, Teacher Assessment, Competencies, Reflective Practice, Teacher Subjectivity.

\section{INTRODUCCIÓN}

Frecuentemente se escuchan lamentos entre profesorado y estudiantado respecto a diversas prácticas escolares; la investigación educativa se ha abocado al estudio de los problemas que afectan a la escuela y sus actores, sin embargo, esto no es suficiente para intentar resolver la problemática. No basta con la denuncia de la situación que se vive en las escuelas, es indispensable que haya un replanteamiento del sistema educativo 
en México, integrando propuestas de cambio en la institución escolar, las autoridades educativas, personal docente y en las estrategias formativas.

A fin de trascender la denuncia y generar propuestas a partir de la investigación educativa, el presente artículo tiene como objetivo desarrollar una propuesta de intervención asociada a los procesos de formación y evaluación docente a partir de los hallazgos encontrados en la investigación elaborada como mi tesis doctoral (Arreola, 2014). Dicha investigación se fundamentó en propuestas metodológicas de corte cualitativo, las cuales dan importancia a la manera como se construye e interpreta la realidad social (Taylor y Bogdan, 1987). Se consideró fundamental investigar el mundo social desde el punto de vista de los actores; la perspectiva de estos se toma como punto de partida empírico, lo cual implica entender el contexto de la conducta o los sistemas de significados empleados por un grupo o por una sociedad particular. Ello permite hacer una reconstrucción de carácter descriptivo de lo que se dice y hace en la escuela y el aula, e interpretativo de lo que puede estar sucediendo o provocando en ese contexto. En dicho estudio se utilizó como instrumento la entrevista a profundidad, la cual recuperó la narrativa oral de estudiantes de una escuela secundaria del sur de la Ciudad de México. El análisis de resultados se ejecutó a partir de la definición de categorías empíricas y analíticas surgidas de las respuestas de las personas entrevistadas, que aunadas a las categorías teóricas permitieron de-construir, describir, comprender e interpretar lo que sucede en el aula: los significados de las y los estudiantes, los desempeños docentes, las prácticas educativas y la forma de interactuar de los actores sociales con y en el entorno escolar.

La propuesta aquí desarrollada asume que el camino hacia la mejora de la práctica docente es el fortalecimiento y la transformación, a través de considerar a esta práctica como una actividad eminentemente reflexiva. Se parte del supuesto que en la formación profesional del personal docente, tanto en lo cognitivo como en lo personal y social, lo socioafectivo constituye una condición necesaria para un desarrollo personal y social satisfactorio, pues no solo impacta en la enseñanza sino también en el aprendizaje.

\section{MARCo TEÓRICO}

Actualmente y después de la reforma de la educación básica en México (2011, 2016), uno de los retos más grandes es la articulación de sus tres niveles básicos para configurar un solo ciclo formativo con propósitos comunes, prácticas pedagógicas congruentes, así como formas de organización y relación interna que contribuya al desarrollo del alumnado competentes y a su formación como ciudadanos. Los elementos centrales en la definición del nuevo currículo que comparten los tres niveles educativos son: Enfoque por competencias, Aprendizaje por proyectos y Evaluación por competencias.

Uno de los principales fines de la educación formal debería ser equipar al estudiantado con instrumentos intelectuales para educarse a sí mismos a lo largo de toda su vida. Lo cual es una aspiración de la actual reforma educativa en México, esta incorpora el modelo de competencias que, a su vez, reconoce que en el mundo global en el cual se vive y con la actual producción de conocimiento resulta fundamental formar al alumnado para enfrentar la incertidumbre y proveerlos de instrumentos y habilidades de pensamiento que les permitan enfrentar los retos y problemas que le presente la vida.

Para fines de este trabajo se retoma la concepción de la UNESCO (1999 citado en Argudín, 2009), la cual señala que una competencia se define como el conjunto de comportamientos socioafectivos y habilidades cognitivas, psicológicas, sensoriales y motoras que permiten llevar a cabo adecuadamente un desempeño, una función, una actividad o una tarea. Sin embargo, esto será posible en la medida que se cuenta con docentes competentes y comprometidos con su función social, de ahí la relevancia de la propuesta que aquí se incluye, pues tiene como finalidad formar docentes competentes.

Para instrumentar un modelo educativo por competencias es necesario que el profesorado cuente con las competencias docentes que posibilitarán el desarrollo de las competencias en el estudiantado. Puntualizando, 
una reforma educativa que contempla como eje organizador a las competencias implica cambios en la docencia, en la forma de relacionarse con los conocimientos y el alumnado.

Son diversos los autores que han señalado las competencias docentes, entre ellos a continuación se revisan las propuestas de Perrenoud (2004), Frade (2008) y Marchesi (2008).

Para Perrenoud (2004), el concepto de competencia representa una capacidad de movilizar varios recursos cognitivos para hacer frente a un tipo de situaciones. Este autor propone diez competencias prioritarias en la formación del profesorado: 1) Organizar y animar situaciones de aprendizaje, 2) Gestionar la progresión de los aprendizajes, 3) Elaborar y hacer evolucionar dispositivos de diferenciación, 4) Implicar a las y los alumnos en su aprendizaje y en su trabajo, 5) Trabajar en equipo, 6) Participar en la gestión de la escuela, 7) Informar e implicar a los padres, 8) Utilizar las nuevas tecnologías, 9) Afrontar los deberes y los dilemas éticos de la profesión y 10) Organizar la propia formación continua.

El modelo propuesto por Frade (2008) señala que una competencia se define como una capacidad adaptativa, cognitivo-conductual, específica que se despliega para responder a la demanda que se produce en un entorno determinado en un contexto sociohistórico y cultural. En síntesis, las competencias integran los conocimientos, habilidades, destrezas y actitudes, pero además la capacidad de poder pensar, resolver problemas, adaptarse al mundo moderno y desarrollar todas aquellas habilidades de pensamiento superior que antes no se consideraban. Frade (2008) propone como competencias docentes: 1) Diagnóstica, 2) Cognitiva, 3) Ética, 4) Lógica, 5) Empática, 6) Comunicativa, 7) Lúdico-didáctica y 8) Metacognitiva de la educación.

Para Marchesi (2008), las competencias profesionales del grupo docente son: 1) Ser competente para favorecer el deseo de saber del estudiantado y para ampliar conocimientos, 2) Estar preparado para velar por el desarrollo afectivo de las y los estudiantes y por la convivencia escolar, 3) Ser capaz de favorecer la autonomía moral del alumnado, 4) Ser capaz de desarrollar una educación multicultural, 5) Estar preparado para cooperar con la familia y 6) Poder trabajar en colaboración y en equipo con los compañeros.

\section{Metodología}

Como se mencionó anteriormente, la presente propuesta es producto de los hallazgos de la investigación ejecutado por Arreola (2014), la cual implicó el análisis cualitativo de las entrevistas a profundidad y sus narrativas orales. Se trata de una investigación de corte cualitativo con una metodología basada en el interaccionismo simbólico y la oralidad; la población de investigación fue reducida, se entrevistó a 12 adolescentes con edades entre los 12 y los 16 años de una escuela secundaria pública, turno vespertino, al sur de la Ciudad de México. La entrevista se aplicó a cuatro estudiantes de cada grado, seleccionados al azar, representativos del conjunto de prácticas académicas habituales. Con ello, el procedimiento analítico puede ser aplicado al análisis teórico de aspectos de la vida social empírica de las y los estudiantes de secundaria.

El ordenamiento metodológico seguido operó bajo una lógica de deconstrucción y construcción del objeto, en dónde la teoría no es un acto de enunciación sino un acto de relación el cual permite explicar una realidad y tomar un posicionamiento personal que faculta construir, junto con los teóricos, al objeto de estudio; se hace un esfuerzo de articulación entre el dato empírico y la teoría, entretejiéndolos para la argumentación y explicación de esa realidad. En dicho estudio exploratorio se utilizó como instrumento la entrevista a profundidad, recuperando la narrativa oral de estudiantes.

Dado que el objetivo de este artículo es presentar la propuesta de formación y evaluación docente, únicamente se presenta de manera sintética el procedimiento metodológico seguido mediante el siguiente esquema (Figura 1). 


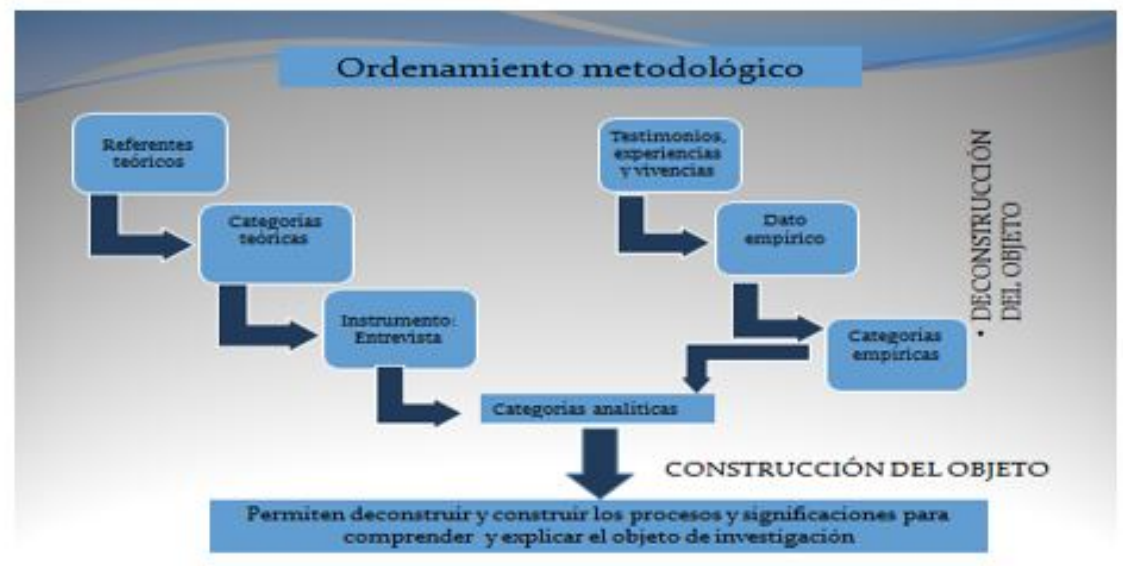

FIGURA 1

Ordenamiento metodológico

Fuente: Arreola (2014)

Las categorías que se trabajaron en dicha investigación fueron (Tabla 1):

TABLA 1

Categorías de análisis

\begin{tabular}{|c|c|}
\hline Categoria teóricas & Categorias empirico-analíticas \\
\hline $\begin{array}{l}\text { A) Educación secundaria } \\
\text { como espacio de } \\
\text { formación }\end{array}$ & $\begin{array}{l}\text { Significado de la escuela } \\
\text { Significado de ser estudiante }\end{array}$ \\
\hline B) Cultura escolar & $\begin{array}{l}\text { Rutinas escolares y } \\
\text { ordenamientos didácticos. } \\
\text { Percepción de las y los } \\
\text { estudiantes por las y los } \\
\text { docentes . Clima escolar. } \\
\text { Ordenamientos disciplinares }\end{array}$ \\
\hline $\begin{array}{l}\text { C) Competencias } \\
\text { docentes socioafectivas }\end{array}$ & $\begin{array}{l}\text { Significado de buen y mal } \\
\text { profesor . Estilo de aprendizaje } \\
\quad \text { Estilo de enseñanza. } \\
\text { Relación maestro-alumno. } \\
\text { Motivación }\end{array}$ \\
\hline $\begin{array}{l}\text { D) Impacto en el } \\
\text { aprendizaje y el } \\
\text { desarrollo. }\end{array}$ & $\begin{array}{l}\text { Percepción de bienestar } \\
\text { Percepción de malestar }\end{array}$ \\
\hline
\end{tabular}

Fuente: Tomado de Arreola (2014)

\section{Resultados}

Los hallazgos encontrados de acuerdo con las categorías trabajadas dan cuenta de que a pesar de que el estudiantado es considerado declarativamente sujetos centrales del esfuerzo educativo, y bajo esta consideración se estructuran todas las actividades, generalmente las necesidades e intereses del alumnado no son tomadas en cuenta. Es decir, parten de supuestos quizá bien intencionados, pero en frecuentes ocasiones no corresponden a las expectativas ni a los intereses del estudiantado, siendo sometidos a lo que los adultos, profesorado y autoridades determinan, generando un sentimiento de incomprensión o resistencia. 
De acuerdo con lo encontrado, las prácticas son rutinarias, la monotonía de la cotidianidad convierte a la escuela en una prisión o en una bomba de tiempo en la que tarde o temprano el/la estudiante tiene que desplegar su energía y su derecho a ser escuchado/a y tomado/a en cuenta. De acuerdo con Sandoval (2000), en la escuela secundaria se espera que el estudiantado asimile una gran cantidad de información que raras veces se relaciona entre sí. En la transmisión de conocimientos se generan lógicas distintas entre estudiantes y docentes; en los primeros existe una escisión entre lo que la escuela les proporciona y sus requerimientos e intereses; por lo tanto, cumplen de manera formal en la escuela sin vincular el conocimiento con su vida cotidiana. Estas lógicas distintas podrían explicar la percepción de las y los estudiantes entrevistados.

Asimismo, según los testimonios se puede suponer que la escuela tiene prácticas impositivas, autoritarias y heterónomas que no favorecen el desarrollo moral autónomo del estudiantado, pese a que esto representa una aspiración educativa: formar un sujeto autónomo. Pero ¿cómo lograrlo si la escuela está cargada de directrices, normas y pautas que son impuestas y no permiten a los sujetos en formación pensar, analizar, reflexionar y tomar decisiones? No se puede esperar que mágicamente al llegar a la edad adulta el individuo se convierta en un ser autónomo, en un ciudadano responsable, cuando no se ha posibilitado el desarrollo de estas cualidades.

Por otro lado, se encontró que frecuentemente el personal docente se queja de la rebeldía que muestra el estudiantado, particularmente los adolescentes, pero cabría preguntarse hasta qué punto es la propia cultura escolar y las prácticas que en la escuela se ejecutan, las que promueven que esta rebeldía se haga patente como una reacción lógica al conjunto de rutinas, monotonía, imposiciones, prohibiciones, falta de comprensión y mínima escucha hacia el alumnado.

También se observa una clara predominancia de lo cognitivo sobre los socioafectivo, aspecto del cual el alumnado se lamenta y lo expresan como una carencia importante. En este sentido, esta situación exige a las y los docentes competencias técnico-pedagógicas y socioafectivas, a fin de contribuir a la apropiada formación del alumnado, el desarrollo emocional y la acertada utilización de los mecanismos de funcionamiento institucional y, con ello, crear un clima de convivencia satisfactorio. Como señala Elsie Rockwell (1986 citado en Sandoval, 2000) ser maestro, sobrevivir durante años al trabajo en el aula, requiere mucho más que el conocimiento de la teoría pedagógica y contenidos escolares. Implica siempre una cantidad de conocimientos más sutiles, generados en esos puntos donde se cruzan lo afectivo y lo social con lo intelectual con el trabajo docente.

De acuerdo con los datos encontrados se puede suponer que el desempeño escolar está influido por factores imputables no solo al estudiante como comúnmente se aprecia, sino también a factores atribuibles al docente en tanto este no promueve la motivación en el alumnado mediante el uso de estrategias y actividades versátiles, atractivas e interesantes de acuerdo con las características de la población estudiantil que se atiende, así como la promoción de la participación activa, lo que para el estudiantado representaría una clase "divertida". Así el profesorado juega un papel fundamental en el proceso de aprendizaje; en mucho, de él depende que el alumnado se involucre y se comprometa en este proceso, se sientan atendidos, tomados en cuenta; en otras palabras, retomar los aspectos socioafectivos como factor favorable para potencializarlos.

En términos generales, de acuerdo con lo expresado por estudiantes se puede comentar que la reforma educativa que se ha instituido en México no ha logrado concretarse en cuanto al enfoque por competencias propuesto, pues el cuerpo docente no evidencia prácticas orientadas al desarrollo de ellas, ni tampoco de poseer las competencias docentes que se esperaría o requerirían.

Dados los hallazgos de la investigación, se considera fundamental empeñar esfuerzos en la formación docente articulada con el desarrollo de competencias tanto técnico-pedagógicas como socioafectivas con su respectivo efecto en la práctica docente y en la formación de las y los estudiantes, ya que se puede conjeturar que existe una relación entre las competencias docentes socioafectivas -e incluso técnico-pedagógicas- y el nivel de percepción de bienestar o malestar, pues este se asocia con conductas y actitudes de las y los docentes. La propuesta de formación y evaluación docente, objeto del presente artículo, pretende atender lo antes señalado desde una perspectiva de la práctica reflexiva. 
Si se concibe a la cultura en términos simbólicos o representacionales, el cambio cultural tendrá que manifestarse en forma de movimientos o desplazamientos de significados y de la constelación simbólica que los sustenta. La escuela se encuentra desfasada de esta realidad social y debe integrarse a la complejidad del mundo globalizado, valiéndose de todos aquellos recursos humanos, institucionales y tecnológicos necesarios, favoreciendo un ambiente escolar dinámico lo más auténtico y semejante al contexto real del estudiantado, diversificando las metodologías didácticas, enfrentando al alumnado a retos y problemas que demanden de ellos una solución, haciendo de los aprendizajes algo funcional para la vida y desarrollando habilidades de pensamiento para enfrentar la incertidumbre pero, sobre todo, incorporar a las prácticas educativas aspectos de índole afectivo-emocional. Resulta apremiante contar con un perfil docente que contribuyan a configurar dicho clima psicosocial y, a su vez, a desarrollar las competencias del alumnado orientadas a responder a los retos de la vida; para ello a continuación se desarrolla una propuesta.

\section{Propuesta de formación y evaluación docente}

Esta propuesta se orienta a atender las necesidades evidenciadas en la investigación previamente efectuada (Arreola, 2014); la propuesta contempla cuatro ámbitos de atención e impacto: la institución escolar, el ambiente escolar, las competencias docentes y el sentido de bienestar, en ellos se encuentran involucrados los diferentes actores sociales de la escuela.

La propuesta está conformada por tres aspectos fundamentales para el buen funcionamiento de la institución escolar: 1) los actores sociales y las transformaciones implicadas; 2) los cambios en las prácticas educativas; y 3) la propuesta de un sistema de competencias docentes para la formación y la evaluación del profesorado.

Asimismo, la propuesta que aquí se sustenta asume la formación docente como un proceso de desarrollo profesional en el cual el ejercicio y enunciación reflexiva se constituye en un dispositivo para transformar la práctica docente y configurar una identidad. La propuesta pretende atender no solo la esfera cognitiva sino enfatizar la importancia de los aspectos socioafectivos en la formación. Piloneta (2006) investigó sobre las competencias técnico-pedagógicas de las y los docentes, sin embargo, la implicación emocional y socioafectiva del trabajo docente sobre la formación del alumno, particularmente del adolescente, no ha sido muy trabajada.

\section{1) Actores sociales}

Se parte del supuesto de que para poder generar cambios es ineludible impactar en los actores sociales participantes en la institución escolar, por ello se propone:

- Formación de las autoridades educativas

- Formación docente

- Coparticipación de madres y padres de familia y comunidad

- Compromiso del estudiantado

En la experiencia laboral con docentes de educación básica frecuentemente se escucha entre ellos un sentimiento de soledad y abandono por parte de las autoridades de todos los niveles, incluyendo los directivos de las escuelas. De acuerdo con testimonios de docentes de educación básica que estudian en la Universidad Pedagógica Nacional (UPN), en variadas ocasiones intentan innovar o poner en práctica los aprendizajes adquiridos durante su tránsito por la Licenciatura en Educación o por la Maestría en Educación Básica y los directivos no son copartícipes, inclusive se oponen por falta de conocimiento o por imposición arbitraria. 
Las autoridades educativas deben ser el inicio del hilo conductor el cual guíe, norme y dé sentido a las prácticas educativas, asimismo deben trabajar en concordancia con el grupo de docentes que esté a su cargo; solo así, en colectivo y en trabajo colegiado, se hará posible trabajar en la búsqueda de una meta educativa: la formación integral del estudiantado, de los futuros ciudadanos. Es fundamental que el trabajo colegiado esté sustentado en prácticas reflexivas sobre el quehacer educativo, para que desde una postura autocrítica se develen las problemáticas o factores que impiden el logro educativo, así como también los aciertos y cualidades se vayan consolidando, a fin de mejorar y transformar las prácticas educativas en beneficio de la formación de la sociedad.

En este sentido, la reflexión de la propia práctica como un hábito de pensamiento y de acción, habrá de trastocar el ser docente y posibilitar la transformación de la subjetividad de las y los docentes mediante la sensibilización, el reconocimiento del impacto de sus acciones y de la relevancia de su función en la constitución de otro ser: el y la estudiante.

Por otro lado, dado que son las y los docentes quienes interactúan de manera directa, constante y cotidiana con las y los estudiantes, es fundamental el desarrollo de competencias no solo propias de la disciplina que imparten o técnico-pedagógicas sino, además, competencias comunicativas, sociales, afectivo-emocionales, éticas y de superación profesional permanente. Solo en la medida que el profesorado sea competente estará en posibilidad de resolver eficazmente los problemas que su quehacer docente le pone a prueba todos los días, asimismo estará en condiciones de responder a las necesidades y retos que le demanda la función educativa y la sociedad.

Otro actor social el cual influye en el proceso educativo es la familia y la comunidad en general, pues estos pueden constituir un elemento facilitador u obstaculizador de los procesos; de ahí que sea sustancial que estén informados y sensibilizados de las innovaciones que se pretenden, a fin de que se conviertan en un agente compresivo y colaborativo de las acciones y tareas que se emprenden en la escuela. Muchas de las exigencias de los padres obedecen a la falta de conocimiento de las implicaciones formativas de las acciones que se efectúan en la escuela y es este desconocimiento lo que las hace justificables. Sin embargo, es tarea del colectivo escolar comunicar, involucrar y comprometer a los padres y a la comunidad para el buen logro de la formación de las y los estudiantes.

El alumno es el actor social sin el cual no tendría sentido la educación, es el protagonista de su propio aprendizaje y, por tanto, el nivel de compromiso que este asuma determinará, en mucho, el logro educativo. Considerando que la niñez y la juventud de hoy son el ciudadano del mañana, la forma como se forja a estos y estas jóvenes será la forma como se desarrolle la sociedad en un futuro cercano.

Es tarea de los profesionales de la educación, contribuir a la formación de un círculo virtuoso en el que el bienestar de las y los docentes se refleje en el bienestar del alumnado y este retribuya satisfacción y éxito para ambos actores. De acuerdo con Zabala y Arnau (2008) el papel del profesorado y del alumnado y, en concreto, las relaciones que se producen en el aula entre ellos, afecta el grado de comunicación y los vínculos afectivos que se establecen y que dan lugar a un determinado clima de convivencia.

La escuela debe profundizar los procesos interpersonales que tienen lugar, tanto en el micro mundo social formado por escolares entre sí, como en el macro mundo social constituido, además por directivos y docentes; relaciones que a veces se tornan más complejas de lo que a simple vista se advierte. De acuerdo con Cerezo (1997) se habla de un complejo mundo afectivo y emocional que se presenta en las relaciones interpersonales.

Para asegurar que el cuerpo docente sea capaz de favorecer el desarrollo del alumnado y de gestionar los conflictos que se produzcan, es necesario que también el personal docente cuide su desarrollo emocional. Solo de esta forma se sentirán seguros para buscar nuevas estrategias que les permitan enfrentarse con acierto y satisfacción a las tensiones afectivas que provoca el estudiantado, especialmente aquellos con problemas emocionales y de conducta. Por otro lado, el personal docente debe considerar que determinadas experiencias emocionales están en la base de las conductas prosociales y de solidaridad. 
El desarrollo afectivo del alumnado contribuye a su bienestar y a su felicidad, pero también favorece una actitud positiva ante el aprendizaje y un comportamiento sensible ante las necesidades de los otros; situación que en un país como México resulta trascendental, pues solo siendo sensibles a las necesidades de otros, se estará en posibilidades de educar a la ciudadanía para vivir en armonía en ciudades tan grandes y cosmopolitas como la Ciudad de México, ahora tan carentes de respeto y tolerancia. Es decir, se trata de una competencia necesaria para poder convivir en grupo, en sociedad y con la naturaleza. De ahí la importancia de que las y los docentes sean conscientes de sus posibilidades de intervención en el ámbito socioafectivo y tengan la competencia suficiente para hacerlo de forma satisfactoria.

\section{2) Prácticas educativas}

En la Tabla 2 se explicitan algunas propuestas de cambio educativo, específicamente en el ámbito de la práctica docente y en la forma de relacionarse e interactuar con el estudiantado, en donde se propone transitar de las condiciones y prácticas que hoy prevalecen hacia otras propicias para una educación alternativa orientada a la formación integral y que para ello exige una docencia reflexiva. 
TABLA 2

Propuesta de cambio educativo

\begin{tabular}{|c|c|}
\hline De. & Hacia \\
\hline Certeza & Incertidumbre, complejidad \\
\hline $\begin{array}{l}\text { Desvinculación del presente } \\
\text { socioeconómico, cultural y personal }\end{array}$ & $\begin{array}{l}\text { Contextualización en la realidad local, } \\
\text { aprendizajes funcionales }\end{array}$ \\
\hline $\begin{array}{l}\text { Desatención /descalificación de } \\
\text { intereses, expresiones }\end{array}$ & $\begin{array}{l}\text { Atención a las necesidades e intereses del } \\
\text { y la estudiante }\end{array}$ \\
\hline $\begin{array}{l}\text { Centrado en la enseñanza, énfasis en } \\
\text { la transmisión de conocimientos } \\
\text { Exposición, repetición }\end{array}$ & $\begin{array}{l}\text { Centrado en el aprendizaje, énfasis en el } \\
\text { desarrollo de habilidades de pensamiento, } \\
\text { capacidad creativa y el emprendimiento. } \\
\text { Modelaje cercano y abierto centrado en el } \\
\text { desempeño orientado a la solución de } \\
\text { problemas. }\end{array}$ \\
\hline Centrado en el conocimiento & $\begin{array}{l}\text { Centrado en el desarrollo integral, el } \\
\text { desempeño, la motivación, la } \\
\text { metacognición, los factores socioafectivos, } \\
\text { la promoción de creencias de autoeficacia }\end{array}$ \\
\hline Metas educativas burocráticas & $\begin{array}{l}\text { Metas educativas formativas y } \\
\text { ciudadanas, formar para la vida }\end{array}$ \\
\hline $\begin{array}{l}\text { Intencionalidad educativa basada en } \\
\text { las metas del y la docente Enseñanza } \\
\text { instruccional }\end{array}$ & $\begin{array}{l}\text { Intencionalidad educativa basada en las } \\
\text { metas del programa y del y la estudiante. } \\
\text { Aprendizaje autorregulado }\end{array}$ \\
\hline Docente transmisor & $\begin{array}{l}\text { Docente mediador con confianza en su } \\
\text { eficacia instructiva }\end{array}$ \\
\hline Alumno receptor & $\begin{array}{l}\text { Estudiante participativo, activo, } \\
\text { autorregulado, con creencias de } \\
\text { autoeficacia académica }\end{array}$ \\
\hline Conocimientos no problematizados & $\begin{array}{l}\text { Conocimientos situados, problematizados, } \\
\text { útiles, en la complejidad de la realidad }\end{array}$ \\
\hline Métodos tradicionales & Métodos interactivos, activos \\
\hline Atención en el error & $\begin{array}{l}\text { Atención en el proceso, considerando el } \\
\text { error como oportunidad de aprendizaje }\end{array}$ \\
\hline $\begin{array}{l}\text { Reconocimiento como cumplimiento de } \\
\text { tareas y opción a descalificar }\end{array}$ & $\begin{array}{l}\text { Reconocimiento de la diversidad de áreas, } \\
\text { aciertos y oportunidades }\end{array}$ \\
\hline $\begin{array}{l}\text { Evaluación focalizada en resultados y } \\
\text { orientada hacia el control }\end{array}$ & $\begin{array}{l}\text { Evaluación formativa centrada en } \\
\text { conocimientos previos, procesos, } \\
\text { resultados y desempeños }\end{array}$ \\
\hline $\begin{array}{l}\text { Moral educativa heterónoma (cumplir } \\
\text { el ideal de cómo ser) Jerarquización, } \\
\text { obediencia, sumisión }\end{array}$ & $\begin{array}{l}\text { Moral educativa autónoma Búsqueda del } \\
\text { Sentido de vida, actuación autónoma, } \\
\text { reflexionada y por convicción. }\end{array}$ \\
\hline
\end{tabular}

Fuente: Tomado de Arreola (2014).

De acuerdo con Flores y De la Torre (2010) no se puede realmente hablar de cambio si no se institucionalizan nuevas prácticas y condiciones, pasando a ser la forma cotidiana de actuar en la escuela. De ahí que sea necesario reiterar la importancia de sustentar una propuesta de formación basada en prácticas reflexivas.

Aquí se asume que la apropiación del enfoque psicopedagógico tiene, como primera condición, un cambio radical en la percepción de su propia práctica. Es decir, implica que los educadores transiten de un tipo de subjetividad a otro diferente, a partir de la reflexión de sus prácticas y el diálogo con los teóricos; lo cual conlleva necesariamente una reconstrucción de la identidad docente. Dicha transformación no puede ejecutarse por decreto, por la aplicación mecánica de un enfoque o por una capacitación en cascada a través de cursos fragmentados de actualización; por el contrario, es preciso influir de manera decidida y profunda en los procesos sistemáticos de formación y evaluación del personal docente y promover prácticas reflexivas 
y de investigación como prerrequisito para la transformación de la percepción de la enseñanza y, por ende, de las prácticas educativas.

Es ineludible que el cuerpo docente se apropie de sus procesos formativos y construyan sus propios significados y sentidos para que realmente haya un cambio educativo. Lo anterior, requiere de instituir políticas educativas que viabilicen estas iniciativas. Si bien es cierto que poco se invierte en educación, no se debe desfallecer ante esta situación, pues existen cambios que pueden concretarse pese a esta carencia, dado que obedecen más a cuestiones de índole actitudinal y de formación de los actores.

Rodríguez (2000) señala que es necesario construir un espacio de pensamiento rebelde que estimule la creación de categorías disidentes de análisis. Una vía es recuperar el saber procedente de las prácticas cotidianas desarrolladas para mejorar la educación, recogiendo el conocimiento que se esconde en esas iniciativas, ejercer una docencia reflexiva e innovar desde las trincheras. A esta última vía es a la que se le apuesta, los soñadores confían en que la educación es un medio posible para transformar la sociedad y la realidad, de lo contrario ¿cuál sería el sentido de esta profesión y de este trabajo?

Bandura (1999) menciona que la tarea de crear ambientes conducentes al aprendizaje reside en gran medida en el talento y autoeficacia de las y los docentes. Las pruebas demuestran que la atmósfera de la clase está determinada en parte por las creencias del profesorado en relación a su eficacia instructiva.

En la Tabla 3 se explicitan las transformaciones a las que se aspira arribar a partir de generar cambios en los actores sociales. 
TABLA 3

Transformaciones esperadas por ámbito educativo

\begin{tabular}{|c|c|}
\hline Ambito & Se aspira trasformar a partir de: \\
\hline $\begin{array}{l}\text { Prácticas } \\
\text { educativas }\end{array}$ & $\begin{array}{l}\varnothing \text { Impactar en la subjetividad docente y } \\
\text { Superar el desconocimiento para avanzar hacia } \\
\text { la apropiación del modelo educativo. } \varnothing \\
\text { Modificar actitudes de indiferencia a favor del } \\
\text { desarrollo de competencias docentes } \\
\text { socioafectivas. } \varnothing \text { Trascender el ámbito de lo } \\
\text { cognitivo recuperando la dimensión } \\
\text { socioafectiva. }\end{array}$ \\
\hline Clima escolar & $\begin{array}{l}\varnothing \text { Renunciar a prácticas de interacción hostil o } \\
\text { indiferente en favor de prácticas sociales } \\
\text { cordiales, respetuosas, motivadoras y } \\
\text { armónicas con predominancia de la confianza } \\
\text { sobre la desconfianza, de la comprensión sobre } \\
\text { la incomprensión, del afecto sobre la } \\
\text { indiferencia, del compromiso sobre la } \\
\text { irresponsabilidad } \varnothing \text { Crear ambientes } \\
\text { conducentes de aprendizaje y desarrollo } \\
\text { integral sustentados prácticas cordiales. }\end{array}$ \\
\hline $\begin{array}{l}\text { Gestión } \\
\text { escolar }\end{array}$ & $\begin{array}{l}\varnothing \text { Transitar de una estructura escolar } \\
\text { jerárquica a una estructura con matiz de } \\
\text { horizontalidad, de trabajo en colectivo o en } \\
\text { comunidades de aprendizaje para atender las } \\
\text { necesidades y problemáticas educativas. }\end{array}$ \\
\hline $\begin{array}{l}\text { Ordenamientos } \\
\text { didácticos }\end{array}$ & $\begin{array}{l}\varnothing \text { Transitar del uso de ordenamientos } \\
\text { didácticos pasivos, rutinarios, áridos y } \\
\text { monótonos hacia ordenamientos activos, } \\
\text { diversificados, versátiles, atractivos y } \\
\text { motivadores. }\end{array}$ \\
\hline $\begin{array}{l}\text { Eficacia } \\
\text { instructiva }\end{array}$ & $\begin{array}{l}\varnothing \text { Robustecer en las y los docentes la confianza } \\
\text { en su eficacia instructiva, favoreciendo la } \\
\text { creación de experiencias de dominio para sus } \\
\text { estudiantes. } \varnothing \text { Impedir la inseguridad de la } \\
\text { eficacia instructiva para evitar generar } \\
\text { ambientes negativos en la clase que suelen ser } \\
\text { tendentes a minar el sentido de la eficacia y el } \\
\text { desarrollo cognitivo de las y los estudiantes. } \varnothing \\
\text { Abandonar la orientación custodial por el } \\
\text { fomento del desarrollo de los intereses } \\
\text { intrínsecos y la autodirección de las y los } \\
\text { estudiantes. }\end{array}$ \\
\hline $\begin{array}{l}\text { Creencias de } \\
\text { autoeficacia } \\
\text { académica }\end{array}$ & $\begin{array}{l}\varnothing \text { Fomentar el desarrollo de creencias de } \\
\text { autoeficacia en el estudiantado, considerando } \\
\text { que el personal docente debe convertirse en un } \\
\text { agente de persuasión social. } \varnothing \text { Transformar } \\
\text { cognitivamente las situaciones amenazantes en } \\
\text { situaciones benignas. }\end{array}$ \\
\hline $\begin{array}{l}\text { Imagen } \\
\text { docente }\end{array}$ & $\begin{array}{l}\varnothing \text { Ambicionar y trabajar en la búsqueda del } \\
\text { desarrollo de las características del buen } \\
\text { profesor y descartando los rasgos identificados } \\
\text { en un mal profesor. }\end{array}$ \\
\hline $\begin{array}{l}\text { Ordenamientos } \\
\text { de la } \\
\text { disciplina } \\
\text { escolar }\end{array}$ & $\begin{array}{l}\varnothing \text { Trascender un modelo autoritario para } \\
\text { ambicionar un modelo de corte más } \\
\text { democrático, en donde los miembros asuman } \\
\text { sus compromisos, responsabilidades y } \\
\text { sanciones, abandonando las prácticas } \\
\text { orientadas al fomento de un desarrollo moral } \\
\text { heterónomo y ocuparse en favor del desarrollo } \\
\text { moral autónomo. } \varnothing \text { Formar estudiantes con } \\
\text { autonomía académica mediante la } \\
\text { implementación de prácticas promotoras de la } \\
\text { reflexión, análisis, metacognición, autogestión, } \\
\text { creatividad y autorregulación en ambientes de } \\
\text { libertad con límites y toma de decisiones. }\end{array}$ \\
\hline
\end{tabular}


Finalmente, se puede asumir que tanto los cambios en los actores sociales como en las prácticas educativas requieren un nuevo perfil docente y la evaluación puede constituirse en un mecanismo para contribuir a formarlo, para lo cual a continuación se propone el sistema de competencias que habrá de guiar estos procesos.

\section{3) Sistema de competencias docentes para la formación y la evaluación del profesorado}

Los teóricos sobre el tema de las competencias no han llegado a acuerdos al respecto, ciertamente la tarea es compleja en tanto el hecho de proponer un modelo de competencias docentes ya está implicando asumir una postura teórica respecto a la función y el rol del y la docente, pues de entrada surgiría la pregunta ¿desde qué enfoque teórico o desde que teoría psicopedagógica está sustentada la propuesta o dichas competencias?

Desde mi experiencia en la UPN, el cuerpo docente llega evidenciando esta carencia y en busca de formación al respecto; el Sistema Educativo Mexicano, deja un margen de flexibilidad demasiado amplio que dificulta darle direccionalidad a la función docente y, con ello, a los procesos de formación y evaluación del profesorado. Dicho lo anterior, las y los docentes de educación básica no cuentan con un modelo de competencias docentes explícitamente asumido o difundido por la Secretaria de Educación Pública; por tanto, se asume la necesidad de puntualizar un modelo de competencias docentes recuperando algunos planteamientos de diversos autores entre ellos: Aubrum y Oriflamma (1990); Zabalza (2003); Perrenoud (2004); Pérez (2005); Hirsch (2005); Valcárcel (2004); Ayala (2008); Subsecretaría de Educación Media Superior [SEMS] (2008); Secretaría de Educación Pública [SEP] (2009); y Tejeda (2009), así como los hallazgos de la investigación de Arreola (2014), por lo que se ha pretendido darse a la tarea de intentar ofrecer una alternativa al respecto.

Para instrumentar un sistema para la formación y la evaluación se propone incluir las siguientes fases:

A) Construcción de un modelo de competencias docentes para la formación y evaluación del profesorado

B) Formación docente

C) Evaluación docente

D) Retroalimentación y toma de decisiones

A continuación, se explican cada una de estas fases.

\section{A. Construcción de un modelo de competencias docentes para la formación y evaluación del profesorado}

El modelo que se propone, constituye un esfuerzo por definir competencias docentes, teniendo en cuenta las siguientes consideraciones:

- Se asume una postura socioconstructivista de la docencia.

- Se trata de una propuesta de competencias genéricas.

- Se considera que cada contexto escolar deberá generar competencias docentes específicas, en consenso y con la participación de los involucrados, tomando en cuenta las necesidades y características de cada institución y cada comunidad.

- La propuesta se orienta hacia la mejora del perfil docente basado en competencias y hacia la función formativa de la evaluación con orientación hacia la mejora y hacia una práctica reflexiva.

- Proponer un modelo de competencias docentes para sustentar la formación de docentes, la práctica educativa y la evaluación de la función docente, así como un conjunto de acciones estratégicas para 
instrumentar y operar dicho sistema de formación y evaluación, desde una perspectiva de práctica reflexiva orientada a la transformación de la subjetividad docente.

- El único interés es intentar dar respuestas y aportar un granito de arena al tan debatido tema de las competencias, en el entendido de que el desconocimiento y la ignorancia de los procesos de innovación han ocasionado que la concreción y operación de los cambios tiendan al fracaso.

En la Tabla 4 se presenta la propuesta del Sistema de Competencias Docentes, organizadas en dos rubros: 1) Competencias técnico-profesionales y 2) Competencias sociopersonales.

TABLA 4

Sistema de Competencias Docentes

\begin{tabular}{|c|c|}
\hline $\begin{array}{l}\text { Competencias } \\
\text { referidas a } \\
\text { desempeños } \\
\text { técnico-profesionales }\end{array}$ & $\begin{array}{l}\text { Competencias psicopedagógicas, } \\
\text { metodológicas y de eficacia instructiva para la } \\
\text { comprensión, fundamentación y ejecución de los } \\
\text { distintos procesos y funciones: motivación, } \\
\text { planeación, diseño de escenarios, mediación, } \\
\text { gestión de progresión de aprendizajes, evaluación, } \\
\text { tutoría y acompañamiento, asi como actividades de } \\
\text { gestión escolar } 2 \text {. Competencias cognitivas y } \\
\text { de dominio de la disciplina } 3 \text {. Competencias } \\
\text { metacognitivas y creativas } 4 \text { Competencias } \\
\text { para utilizar las nuevas tecnologias en la promoción } \\
\text { del aprendizaje } 5 \text {. Competencias para la } \\
\text { reflexión e investigación de los procesos y prácticas } \\
\text { educativas } 6 \text {. Competencias organizativas } \\
\text { para gestionar la propia formación continua } \\
7 \text { Competencias propositivas para contribuir } \\
\text { activamente a la mejora de la calidad, al cambio y } \\
\text { la innovación }\end{array}$ \\
\hline $\begin{array}{l}\text { Competencias } \\
\text { referidas a } \\
\text { desempeños } \\
\text { sociopersonales }\end{array}$ & $\begin{array}{l}\text { 8. Competencias comunicativas } 9 \text {. } \\
\text { Competencias para la construcción de ambientes } \\
\text { conducentes para el aprendizaje colaborativo, } \\
\text { autónomo y autorregulado, asi como para la } \\
\text { formación de creencias de autoeficacia } 10 \text {. } \\
\text { Competencias relacionales y afectivo-emocionales } \\
\text { para la resolución de conflictos, asi como para la } \\
\text { generación de ambientes psicosociales que } \\
\text { promuevan relaciones sanas y de bienestar, } \\
\text { propicias para el desarrollo integral } 11 \text {. } \\
\text { Competencias para el trabajo colaborativo e } \\
\text { institucional } 12 \text {. Competencias para implicar a } \\
\text { los padres de familia y sensibilizar a la comunidad } \\
13 \text {. Competencias éticas para enfrentar deberes } \\
\text { y dilemas propios de la profesión }\end{array}$ \\
\hline
\end{tabular}

Fuente: Elaboración propia

\section{B. Formación docente}

Pavié (2011) considera que la adquisición de las competencias no precede al trabajo, sino que, además de efectuarse en su transcurso, es mediante este como se desarrollan. Aquí es cuando el concepto de competencia toma su actual sentido: son fruto de la experiencia puesta en juego con el fin de construir competencias inéditas.

La formación se concibe como un proceso social y cultural que obedece al carácter de la integridad del desarrollo de la capacidad transformadora humana que se da en la dinámica de las relaciones entre los sujetos 
en la sociedad, en constante y sistemática relación, capaz de potenciar y transformar su comportamiento en el saber, hacer, ser y convivir (Vargas, 2010, p. 3).

Cabe señalar que para la instrumentación de la formación docente se deberán recuperar las competencias docentes genéricas propuestas en el cuadro 4; la institución escolar deberá desarrollar seminarios, debates, trabajo colegiado, cursos y prácticas orientadas al desarrollo de dichas competencias, así como informar y sensibilizar respecto al modelo psicopedagógico que se sustenta. Todas estas estrategias bajo un modelo de docencia reflexiva. Ello implica invertir en los procesos de formación docente, promover programas cuya finalidad no se reduzca a lo informativo, sino que haya un verdadero esfuerzo de análisis y reflexión para implicar al docente y sensibilizarlo, favoreciendo su capacidad analítica, crítica y reflexiva en torno a su quehacer docente y que esto tenga un impacto que se vea reflejado tanto en su práctica docente como en la formación de sus alumnos. En este sentido, se asume que los procesos de formación obedecen a una lógica de deconstrucción y reconstrucción de concepciones, prácticas y discursos, por lo tanto se considera que se trata de procesos continuos y permanentes sustentados en la docencia reflexiva como una acción permanente.

\section{Evaluación docente}

Una vez que se ha cumplido con la fase de formación, se estará en condiciones de evaluar el desempeño docente (tanto de docentes frente a grupo como de directivos de escuela) con el fin de valorar cómo se ha apropiado del modelo psicopedagógico, qué impacto ha tenido este en las prácticas y cuáles son las áreas de oportunidad que requieren seguirse formando. La evaluación docente tiene como finalidad fortalecer la profesión y reflexionar sobre el propio desempeño, con el propósito de lograr mejores resultados en sus alumnos. De acuerdo con Rueda (2009) al tratarse de la docencia, la evaluación puede concebirse también como un recurso para consolidar el reconocimiento social sobre su importancia estratégica en los procesos de formación.

Se busca promover evaluaciones de la docencia orientadas a la función formativa y a la toma de decisiones que posibiliten la mejora de la calidad educativa y no tanto en un sentido de control o de inspección sobre el trabajador educativo. La evaluación no debe constituir una amenaza para el docente, por el contrario, debe representar la oportunidad de identificar sus debilidades y fortalezas, aprender del error y promover la innovación y la actitud propositiva para la transformación y mejora de la intervención educativa, tal como lo señala Rueda (2009):

En el contexto de México se ha respondido con relativa prontitud a los señalamientos de las políticas de evaluación asociadas a compensaciones salariales, obtención de recursos económicos adicionales y exigencias de rendición de cuentas. Sin embargo, al mismo tiempo se constata una presencia muy débil del sentido de la evaluación con fines de mejora. Por tanto, se trata de aprovechar este aire de renovación, motivado por el enfoque por competencias, para sacar partido a la experiencia acumulada y rectificar el rumbo (p.13).

Pasos para la evaluación docente:

1. El primer paso es definir el propósito de la evaluación, en este caso primordialmente la función formativa.

2. El segundo es reconocer la naturaleza de lo que se somete a evaluación, en este caso las competencias docentes claramente explicitadas y propuestas en la Tabla 3.

3. El tercero es definir quién efectuará la evaluación, en este caso se propone al colectivo escolar y al propio profesor, sin olvidar que el objeto de evaluación está dado por los desempeños explicitados en las competencias docentes propuestas. Cabe señalar que dichos desempeños deben ser valorados en la práctica in situ, no desde un examen de conocimiento del programa de estudios como se ha procedido, pues el hecho de que el profesorado conozca el programa y sus fundamentos teóricos no garantiza ni que sea excelente docente ni que sea competente para la docencia. 
4. El cuarto paso es establecer a través de qué medios o fuentes de información se elaborará la evaluación, en este caso se propone que para llevar a cabo la evaluación del desempeño docente de acuerdo con las competencias propuestas y utilizando un enfoque de corte más cualitativo, se sugiere utilizar un abanico de posibilidades que favorezcan la evaluación auténtica y en situación, entre estas:

- Portafolio de productos del y la docente como planeaciones, material didáctico, medios de evaluación, etc. para valorar competencias psicopedagógicas y metodológicas. La elaboración de estos productos requiere necesariamente de un nivel de competencia y refleja el desempeño docente en este ámbito.

- Análisis en colectivo o autoanálisis de videograbaciones de prácticas docentes para valorar competencias sociopersonales y cognitivas, tales como la mediación, las formas de interacción, solución de conflictos, comunicación, dominio de la disciplina, ambiente de aprendizaje, entre otras. Es importante definir los indicadores de desempeño para la valoración de la observación de las videograbaciones, o bien, de observaciones directas.

- Autoevaluación del y la docente para reflexionar sobre la confianza en su eficacia instructiva, sus aciertos, errores, habilidades metacognitivas, creativas, etc., posibilitando la identificación de sus debilidades y fortalezas, a fin de orientar sus nuevos procesos formativos, de capacitación y actualización.

- Sesiones de trabajo colectivo, tales como debates o grupo focal, para evidenciar competencias propositivas, para la reflexión y construcción de rutas de mejora e intervención, así como para la investigación educativa sobre las necesidades y problemáticas que enfrentan en su quehacer cotidiano.

- Formación continua mediante la corroboración de la asistencia a eventos de formación que respondan a sus necesidades y retos educativos.

Las estrategias de evaluación antes mencionadas pretenden impactar en la subjetividad docente y hacer del proceso formativo y evaluativo, una práctica reflexiva mediante una situación vivencial que promueva la apropiación, el involucramiento y el compromiso; es decir, que constituyan principalmente ejercicios intrainstitucionales.

En la propuesta presentada en este artículo se apuesta a la obtención de mejores resultados con una perspectiva que asuma una lógica de adentro hacia afuera.

$\mathrm{Al}$ respecto de la evaluación docente, se discrepa de aquellas prácticas evaluativas sustentadas en exámenes sobre conocimientos pedagógicos exclusivamente, ya que no representan situaciones auténticas y no evidencian el desempeño de las y los docentes en situación, ni en relación a la gestión de los aprendizajes, ni en cuanto a los ambientes relacionales con las y los estudiantes (competencias referidas a desempeños técnico-pedagógicos ni sociopersonales). De ahí que los medios de evaluación antes propuestos estén enfocados en valorar los desempeños docentes en relación a las competencias previamente definidas (Tabla 4), involucrando a los propios sujetos en sus procesos de evaluación.

\section{Retroalimentación y toma de decisiones}

La información arrojada en la evaluación constituye el insumo para tomar decisiones en cuanto a las acciones formativas y las estrategias operativas que el profesorado y directivos requieren. Para ello, es necesario socializar los resultados de la evaluación y analizarlos en colectivo con una mirada crítico-constructiva, pues esto permitirá tomar conciencia de los avances, pero también de los obstáculos y retos que quedan por 
enfrentar, así como identificar las necesidades de formación que se tienen y que habrán de contribuir a solventar las problemáticas de la escuela y de las y los estudiantes.

Asimismo, se propone instituir mecanismos de metaevaluación. Como un proceso democrático de discusión y reflexión para generar una comprensión rica y relevante sobre lo evaluado. En palabras de Santos y Moreno (2004) "No basta interrogarse sobre la calidad de los datos que se recogen en el informe o sobre el rigor de los métodos que se han aplicado para extraer información, sino que es preciso preguntarse por la naturaleza de la iniciativa, por la finalidad del proceso, por las reglas éticas que lo han inspirado, por la utilización que se ha hecho de la información, por el control democrático de los informes, por las secuelas que la evaluación ha dejado". Con el propósito de tener total transparencia se propone utilizar los siguientes mecanismos de metaevaluación:

- Socialización de los resultados de evaluación.

- Análisis en colectivo de los instrumentos de evaluación y los resultados obtenidos.

- Reflexión y retroalimentación en lo individual y lo institucional.

- Participación del profesorado en la toma de decisiones, antes y después del proceso de evaluación.

- Participación del colectivo en las propuestas o alternativas para enfrentar obstáculos, problemáticas, retos e innovaciones identificadas a partir de la evaluación.

\section{Conclusiones}

Si bien los planteamientos vertidos en esta propuesta no solucionan totalmente las problemáticas señaladas, sí puede contribuir a aportar algunos elementos que lleven a la sensibilización, la reflexión, el análisis crítico y a poner sobre la mesa aspectos que hoy ya no se pueden ignorar, los cuales se deben replantear e incorporar a las políticas educativas, asimismo que inspiren a otros a continuar en la búsqueda del cambio que reoriente las prácticas educativas y continúen hacia la mejora. Como señala Bolívar (2014) los cambios educativos y reformas afectan no solo, ni principalmente, a los conocimientos, habilidades o capacidades de las y los docentes, sino más básicamente a las relaciones que tienen en su trabajo, en el núcleo de los procesos de enseñanza y aprendizaje. La cara personal y emocional del cambio educativo ocupa un lugar central en el ejercicio profesional. Ignorar estos aspectos destinará al fracaso de cualquier reforma o cambio educativo.

Se concluye que las competencias docentes referidas a desempeños técnico-profesionales y sociopersonales están impactando en el aprendizaje y el desarrollo de las y los estudiantes, ya sea de manera positiva cuando las y los docentes cuentan con ellas, o bien, de manera negativa cuando carecen de ellas.

Se asume que contar con un perfil de competencias docentes permite guiar los procesos de formación y evaluación del profesorado, lo cual posibilita la operación de los programas de estudio bajo el enfoque de las competencias, tal y como se establece en el discurso oficial del contexto educativo mexicano.

Particularmente, en el presente artículo se considera de vital importancia el desarrollo de aspectos socioafectivos y emocionales en la formación del y la docente. Si se entiende que la competencia integra el saber, el saber hacer y el saber ser, entonces se puede entender la competencia emocional como el conjunto de conocimientos, capacidades, habilidades y actitudes necesarias para comprender, expresar y regular de forma apropiada los fenómenos emocionales y, en consecuencia, los desempeños del y la docente tendrían que promover una relación efectiva con su alumnado y favorecer el cauce adecuado de los procesos de enseñanza y aprendizaje. Necesario recordar que, en ocasiones, los desempeños del cuerpo docente favorecen lo contrario: desmotivación, aburrimiento, falta de interés, rebeldía, etc., lo cual hace que la relación docente-estudiante cobre una importancia incalculable. Según Fernández (2007), dependiendo de la relación que entable un/ a docente con un/a estudiante, sus expectativas para aprender y su confianza irán asociadas con esta. Se enfatiza la necesidad de trascender la excesiva preocupación por favorecer la esfera cognitiva y transformar los procesos y las prácticas educativas, orientándolas hacia una educación integral que priorice la dimensión 
socioafectiva, desarrollando competencias docentes y estudiantiles necesarias que les habrán de permitir enfrentar un mundo globalizado con retos para afrontar la diferencia, la tolerancia, la comunicación, la violencia, la discriminación, etc. y cuyo impacto muy probablemente habrá de permanecer en ellos a lo largo de su vida.

\section{ReFERENCIAS}

Argudín, Y. (2009). Educación basada en competencias. Nociones y antecedentes. México: Trillas.

Arreola, R. (2014). El adolescente de secundaria: Significados en torno a las competencias docentes socioafectivas y su impacto en el desarrollo y el aprendizaje. (Tesis de doctorado). Universidad Nacional Autónoma de México.

Aubrum, S. y Oriflamma R. (1990). Clasificación de competencias. En Zabalza, M. Competencias docentes del profesorado universitario. Calidad y desarrollo profesional (pp. 71-72) Madrid: Nárcea.

Ayala, F. (2008). El modelo de formación por competencias. Recuperado de http://www.modelo.edu.mx/uni/mcom .ppt. (Error 2: El enlace externo http//:www.modelo.edu.mx/univ/mcom.ppt debe ser una url) (Error 3: La url http//:www.modelo.edu.mx/univ/mcom.ppt no esta bien escrita)

Bandura, A. (1999). Autoeficacia: cómo afrontamos los cambios de la sociedad actual. Bilbao: Desclée de Brouwer.

Bolívar, A. (2014) Las historias de vida del profesorado. Revista Mexicana de Investigación Educativa, 19(62), 911-734. Recuperado de http://www.redalyc.org/pdf/140/14031461004.pdf

Cerezo, F. (1997). Conductas agresivas en la edad escolar. Aproximación teórica y metodológica. Propuestas de intervención. Madrid: Ediciones Pirámide.

Fernández, I. (2007). Haciendo frente a la disrupción desde la gestión del aula. En Torrego, J. (2007) Modelo integrado de mejora de la convivencia. Barcelona: Graó.

Flores, E y De la Torre M. (2010). La problemática de la investigación sobre cambio educativo. Revista Mexicana de Investigación Educativa, 15 (47), 1017-1023.

Frade, L. (2008). Desarrollo de competencias en educación: desde preescolar hasta el bachillerato. México: Inteligencia Educativa.

Hirsch, A. (2005). Construcción de una escala de actitudes sobre ética profesional. Revista Electrónica de Investigación Educativa, 7(1), 1-14. Recuperado de http://redie.uabc.mx/vol7no1/contenido-hirsch.html.

Marchesi, A. (2008). Sobre el bienestar de las y los docentes. Competencias, emociones y valores. Madrid: Alianza.

Pavié, A. (2011). Formación docente: hacia una definición del concepto de competencia profesional docente. REIFOP, 14(1), 67-80. Recuperado de https://www.aufop.com/aufop/uploaded_files/articulos/1301587967.pdf

Pérez, J. (febrero, 2005). La formación permanente del profesorado ante los nuevos retos del sistema educativo universitario. En A. García Correa (Presidencia). XI Congreso de Formación del Profesorado, llevado a cabo en Segovia.

Perrenoud, P. (2004). Diez nuevas competencias para enseñar. Barcelona: Graó.

Piloneta, G. (2006). Evaluación de competencias profesionales básicas del docente. Bogotá: Magisterio.

Rodríguez,J. (2000). Las y los alumnos de secundaria: ¿Qué piensan de sus maestros? En Tiempo de educar, 2 (003-004), 160-187.

Rueda, M. (2009). La evaluación del desempeño docente: consideraciones desde el enfoque por competencias. Revista Electrónica de Investigación Educativa, 11(2), 1-16.

Sandoval, E. (2000). La trama de la escuela secundaria: institución, relaciones y saberes. México: Plaza y Valdés/UPN.

Santos, M. y Moreno T. (2004). ¿El momento de la metaevaluación educativa? Consideraciones sobre epistemología, método, control y finalidad. Revista Mexicana de Investigación Educativa, 9(23), 913-931.

Secretaria de Educación Pública (SEP) (2009). Modelo integral para la formación profesional y el desarrollo de competencias del maestro de educación básica. México: SEP. 
Roxana Lilian Arreola Rico. Formación y evaluación docente basada en un perfil por competencias. ...

Subsecretaria de Educación Media Superior (SEMS) (2008). Competencias que expresan el perfil del docente de la educación media superior. Recuperado de https://bit.ly/2XoJ1dc

Taylor, S. y Bogdan, R. (1987). Introducción a los métodos cualitativos de investigación. Barcelona: Paidós.

Tejeda, J. (2009). Competencias docentes. En Profesorado. Revista de Curriculum y Formación del Profesorado, 13(2), $1-15$.

Valcárcel, M. (2004). La preparación del profesorado universitario para la convergencia europea en educación superior. Educatio Siglo XXI, 23, 1-5.

Vargas, L. (2010). La formación docente. Congreso Iberoamericano de educación, Metas 2021. Recuperado de https:// bit.ly/2e53MXe

Zabala, A. y Arnau L. (2008). 11 ideas clave. Cómo aprender y enseñar competencias. Barcelona: Graó.

Zabalza, M. (2003). Competencias docentes del profesorado universitario. Calidad y desarrollo profesional. Madrid: Nárcea.

CC BY-NC-ND 